\title{
Direito Constitucional Quilombola, de Fernando Gallardo Prioeste e Eduardo Fernandes Araújo
}

\author{
[PRIOSTE, Fernando Gallardo Vieira; ARAÚJO, Eduardo
}

Fernandes de (orgs.). Direito constitucional quilombola: análises

sobre a ação direta de inconstitucionalidade $n^{\circ} 3239$. Rio de Janeiro: Lumen Juris, 2015, 145 p.]

\section{Ricardo Prestes Pazello ${ }^{1}$}

"Desenhando o invisível" - esta seria uma boa imagem poética para descrever a tentativa ínsita ao livro organizado por Fernando Gallardo Vieira Prioste e Eduardo Fernandes de Araújo. Intitulando-se Direito constitucional quilombola: análises sobre a ação direta de inconstitucionalidade $n^{\circ} 3239$, a obra tem por fio condutor um esforço anunciado já no prefácio de Carlos Frederico Marés de Souza Filho: remediar

1 Professor de Antropologia Jurídica na Universidade Federal do Paraná (UFPR). Doutor em Direito das Relações Sociais pelo Programa de Pós-Graduação em Direito da Universidade Federal do Paraná (PPGD/UFPR). Mestre em Filosofia e Teoria do Direito pelo Curso de Pós-Graduação em Direito da Universidade Federal de Santa Catarina (CPGD/UFSC). Bacharel em Direito pela UFPR. Pesquisador do Núcleo de Estudos Filosóficos (NEFIL/UFPR) e do grupo de pesquisa Direito, Sociedade e Cultura (FDV/ ES). Secretário geral do Instituto de Pesquisa, Direitos e Movimentos Sociais (IPDMS). Integrante da coordenação do Centro de Formação Milton Santos-Lorenzo Milani (SantosMilani), do Centro de Formação Urbano-Rural Irmã-Araújo (CEFURIA) e do Instituto de Filosofia da Libertação (IFiL). Presidente do Conselho de Representantes da Associação dos Professores da Universidade Federal do Paraná-Seção Sindical do ANDES-SN (CRAPUFPR). Coordenador do projeto de extensão popular Movimento de Assessoria Jurídica Universitária Popular - MAJUP Isabel da Silva, junto à UFPR. Colunista do blogue assessoriajuridicapopular.blogspot.com.br 
a "estranha doença de Garabombo" (p. 8), que aflige os povos e comunidades tradicionais da América Latina, em geral, e do Brasil, em especial. Mas que enfermidade seria esta? A mesma que acometeu a personagem principal de um dos volumes da pentalogia do escritor peruano Manuel Scorza, A guerra silenciosa (escrita entre 1970 e 1979), qual seja, a de ser invisível para o poder posto.

Os advogados populares e pesquisadores Fernando Prioste, assessor jurídico popular da organização de direitos humanos Terra de Direitos e mestrando na Pontifícia Universidade Católica do Paraná, e Eduardo Araújo, integrante da Dignitatis - Assessoria Técnica Popular e doutorando na Universidade de Coimbra, além de professor na Universidade Federal da Paraíba, propõem-se a realizar a importante tarefa de visibilizar os direitos das comunidades quilombolas, tendo por preocupação central afirmá-los constitucionalmente. A missão é tão árdua quanto necessária: ao esboçarem o direito constitucional quilombola, a partir de três dispositivos constitucionais principais (os artigos 215 e 216 do articulado permanente, bem como e principalmente o artigo 68 do Ato das Disposições Constitucionais Transitórias), permitem a visualização da silhueta de direitos que continuam sofrendo ataques dos tradicionais setores da elite brasileira, vinculados ao agronegócio latifundista e ao racista colonialismo estatal. A afirmação de tais direitos é imperiosa já que os citados setores apresentaram suas razões etnocêntricas em Ação Direta de Inconstitucionalidade, de número 3.239, destinada a varrer do ordenamento jurídico nacional o decreto 4.887 de 2003 que regulamenta a demarcação e titulação das terras quilombolas; e o mais trágico: o voto do ministro relator da ação no Supremo Tribunal Federal deu provimento a ela.

Pois bem, o desenovelar da invisibilidade jurídica dos quilombolas se inicia com a evocação que Marés de Souza Filho faz da tradição "garabombônica" de indígenas e quilombolas, assim como de intelectuais - como Clóvis Moura e Abdias do Nascimento - que contribuíram para que a nova ordem constitucional brasileira, a partir de 1988, deslocasse o lugar jurídico dos quilombos do âmbito do crime para o do direito constitucional. Porém, mesmo que reconhecidos, os quilom- 
bolas e suas territorialidades permanecem, na prática, ocultados, por enfrentarem a sanha do capital.

Sendo coerentes com o compromisso da visibilização, Prioste e Araújo incorporam ao livro também um documento da Coordenação Nacional de Articulação das Comunidades Negras Rurais Quilombolas (CONAQ), em defesa do decreto 4.887. Ali o movimento apresenta sua luta histórica e a conecta com a conquista obtida na regulamentação do artigo 68 do ADCT, via referido decreto. O documento é definitivo quanto à visibilização da existência quilombola no Brasil, ao afirmar que "até o final de 2002 o Brasil só sabia da existência de pouco mais de 700 quilombos", mas "hoje o governo certificou mais de dois mil quilombos e reconhece a existência de mais de três mil e quinhentos". E arremata: "mas a CONAQ reconhece que esse número é superior a cinco mil comunidades" (p. 18-19).

A CONAQ, ainda, não titubeia ao apresentar os responsáveis pela ADI 3.239 como os grupos que contra eles se colocam, afinal a invisibilização tem seus artífices. Nesse sentido, "por prevalecer a lei do mais forte, do opressor sobre o oprimido" (p. 16), é que os quilombolas têm sido violentados de todas as maneiras e a declaração de inconstitucionalidade do decreto seria mais uma destas violências, contra a qual se posicionam firmemente.

Outro passo rumo ao desenho do invisível (ou do que foi, conscientemente, invisibilizado) é dado pelo próprio Fernando Prioste ao fazer um minucioso estudo do voto de Cezar Peluso, ministro relator da ADI 3.239, ajuizada em 2004 pelo hoje partido Democratas. O texto de Prioste, é verdade, carrega consigo as marcas do discurso da advocacia, o que só comprova seu compromisso com a causa sob apreço. Ao destrinchar o voto de Peluso, apresenta suas (in)conseqüências, notadamente as que se referem a uma repristinação, digamos, material do decreto 3.912 , de 2001, que foi revogado pelo decreto de 2003, por regulamentar o artigo 68 do ADCT dando-lhe um formato inexeqüível, qual seja, o de exigir uma estapafúrdia ocupação de terras que se comprovasse desde 1888 até 1988 - portanto, ocupação centenária. 
Dentre outras coisas, Prioste demonstra que a interpretação é incoerente com o texto constitucional, que pretende garantir direitos aos quilombolas e não os punir. E mais do que isso, "não são os quilombolas que bebem da Constituição, pois foi a Cara Magna que buscou inspiração nas lutas libertárias dos quilombolas". Ora, não faria sentido, portanto, interditar o acesso aos seus territórios - algo que a exigência de ocupação centenária, na prática, faz.

O arsenal de argumentos é exemplar: a aplicabilidade imediata do artigo 68 do ADCT (independente de lei formal que o regule); a inconstitucionalidade por omissão em caso de afastamento do decreto 4.887; a contradição encontrada em outras decisões do STF, que asseguraram a "realização do direito constitucional à terra dos quilombolas" (p. 35), como no caso do Mandado de Injunção 630; a existência de lei integrativa via recepção formal da Convenção 169 da Organização Internacional do Trabalho, argumento levantado pelo relator; a abundante jurisprudência dos tribunais regionais federais posicionando-se pela constitucionalidade do decreto de 2003; a não inovação na ordem jurídica que o decreto implica, por referir-se a típica relação jurídica entre sujeitos de direito, com objeto, beneficiário, elemento de referência, dever e devedor, conforme se pode extrair do próprio artigo 68.

Sendo definitiva a argumentação a respeito da constitucionalidade da regulamentação feita pelo decreto 4.887 , o fio da meada continua se desenvolvendo com fins a desenhar o invisível. Novo passo importante é dado por Girolamo Treccani, que expõe estudo sintético sobre a existência continental da experiência dos quilombos (ainda que com vários nomes em outros países da América Latina). Ao recolher legislações de países como Bolívia, Colômbia, Equador, Honduras, Nicarágua e Costa Rica, o autor desvela o histórico colonial e escravista que unifica o continente e precisa reparar suas opressões estruturantes. Além desta importante visibilização, Treccani oferece à problemática um panorama sobre a situação das comunidades negras no contexto da Corte Interamericana de Direitos Humanos, enfocando tantos os aspectos concernentes à aplicação da Convenção 169, da OIT, quanto o Pacto de São José da Costa Rica. A contribuição deste estudo é a de afirmar que os direitos humanos são autoaplicáveis, não 
só no contexto internacional, mas igualmente na seara interna, como fica patente na compilação que faz de abundante jurisprudência sobre o assunto. Ademais, a dimensão continental das comunidades negras faz com que Treccani possa afirmar que "os Quilombos não são uma experiência exclusivamente brasileira” (p. 59), o que se faz sentir por todo seu texto, ainda que suas considerações finais, mais preocupadas com o debate interno brasileiro, não reconectem a envergadura latino-americana da questão - obra ainda a ser feita pela teoria crítica do direito no continente.

A senda do desenho visibilizador continua com os artigos seguintes, um, de Igor Almeida, procurando defender o direito a autodefinição dos quilombolas como direito fundamental sem o qual todo o mais resta pendente; e outro enfatizando a luta pelo reconhecimento judicial, em especial no âmbito da jurisprudência constitucionalista, no que pertine aos direitos dos quilombolas. Este último artigo foi escrito por Aline Caldeira Lopes e ele se destaca pelo malabarismo da autora, interessante em si ainda que tenha inevitáveis limites (no mínimo, geopolíticos), em procurar basear sua defesa do reconhecimento constitucional dos direitos quilombolas na teoria hermenêutica constitucionalista européia, evocando clássicos como Ferdinand Lassale e contemporâneos como Antonio Negri e, especialmente, Peter Haberle.

Por fim, o último ensaio do livro é de autoria de Eduardo Araújo, que propõe perquirir sobre o tema da terrritorialidade em "um campo hermenêutico interdisciplinar progressista” (p. 120). Sua reflexão criativa revela um advogado popular que se compromete com a pesquisa e práxis a um só tempo. Isto se apresenta em sua demorada análise da situação da questão quilombola no STF, mas também por sua interpretação da "relação do Estado brasileiro e da sociedade com a dimensão étnico/racial" (p. 125). A defesa de um "estado pluriétnico" baseia-se em uma visão pluralista e interdisciplinar, que põe em xeque o ponto de vista da "ciência jurídica", via de regra comprometida com o dogmatismo que supostamente lhe orientou a existência desde o medievo. Araújo conclui que é uma perspectiva de comprometimento social, muito mais do que qualquer outra coisa, que deve consolidar o desenho constitucional visibilizador dos direitos quilombolas no Brasil. 
O livro se encerra, por sua vez, com o texto da sustentação oral da Vice-Procuradora Geral da República, Debora Macedo Duprat de Britto Pereira, por ocasião de pronunciamento diante do caso da ADI 3.239 no STF. O texto é um belo corolário da obra, por sintetizar, em linguagem própria para quem tem na suprema corte sua interlocutora, o estado da arte dos direitos constitucionais quilombolas, incluindo-se aí o diagnóstico de que as comunidades negras, assim como "todos os grupos que se organizavam de modo diverso da sociedade majoritária foram tornados invisíveis pelas estratégias mais diversas, principalmente sob a forma de recusas a direitos próprios" (p. 140-141). Junto a isto, está a defesa de que o poder se socialize, mesmo que minimamente, com o intuito de permitir o direito de os quilombolas definirem, pela autoidentificação, suas próprias fronteiras, democratizando o estado brasileiro.

Como se pode perceber, trata-se de livro bastante oportuno no quadro atual dos debates do direito público brasileiro no que se refere a temas étnico-raciais e especificamente relacionados a povos e comunidades tradicionais. Ao desinvisibilizar o direito constitucional quilombola, produzido nas margens do pensamento/prática jurídico estabelecido, Prioste e Araújo visibilizam o modo de vida quilombola e também a assessoria jurídica popular que com ela se compromete, além de uma miríade de temas que a nossa racionalidade jurídica colonizada e socialmente desreferenciada não admite entrar em suas fotografias da realidade. 